1. The temperature was mostly subnormal, and never exceeded $99^{\circ}$. 2. The excessive collapse without signs of disease to account for it; all appeared very ill and were despondent about themselves from the first. 3. The dyspncea coming on as the vomiting lessened, and the somewhat sudden fatal termination. That the cases were "algid" cases of malaria seems negatived by the fact that the place in which the patients were living was not a very malarious one and the type of fever occurring there was a very mild one; also by the absence of any fever and in all except the first of any enlargement of the spleen; and also in the only one in which an examination of the blood could be made by the absence from the blood of malarial organisms and pigment. The absence of clinical and post-mortem signs of kidney disease renders uræmia an insufficient explanation. Many of the symptoms point to ptomaine poisoning, though the somewhat long course and the absence of diarrhoea seem against this theory. The only article of food suspected was cow's heel which two of the patients had eaten just before the illness as had one other possibly, and which is a substance from its gelatinous composition offering a particularly suitable nidus for bacterial growth. It was unfortunate that clinical and bacteriological examinations of the stomach contents could not be-made.

Cherat, Punjab, India.

\section{A CASE OF PENTASTOMA CONSTRICTUM.}

By ALBERT J. CHALMERS, M.D. VICT., F.R.C.S. ENG., ASSISTANT COLONIAL SURGKON, THE GOLD COAST COLONY.

BY the kind permission of the Right Honourable the Secretary of State for the Colonies I am permitted to publish an account of this case of pentastoma constrictum.

Early in 1898 a negro, by race a Mendi from Sierra Leone, applied for medical relief at the Colonial Hospital at Accra on the Gold Coast of West Africa. He was admitted into the hospital and in the course of a few days he died. At the necropsy large numbers of the parasite pentastoma constrictum were found in the langs, liver, alimentary canal and peritoneal cavity. As there are not many descriptions of this parasite and of the disease which it causes I consider that a brief account may be useful to anyone interested in tropical diseases.

Pentastoma constrictum was first discovered in 1847 by Pruner $^{1}$ in Egypt in the livers of two negroes upon whom he made post-mortem examinations. He apparently did not recognise the zoological position of the parasite, but sent specimens to Bilharz and Von Siebold, ${ }^{2}$ who published an account of it, and gave it the name of "pentastoma constrictum" in their Text-book of Zoology. The next recorded investigation is that given by Aitken ${ }^{3}$ of a case under the care of Dr. Kearney. This observer records the clinical history of the illness and death together with the post-mortem appearances of a negro private of the West Indian Regiment who died in January, 1865, at Jamaica, but who had come from St. Helena only eight months previously. After this there is apparently a long interval without any further records till Girard published an account of the illness and death from purulent meningitis of a Senegalese tirailleur sent to him by Dr. Marchoux and Dr. Clouard. These gentlemen had found in the liver of the tirailleur the characteristic cysts containing the parasite. The patient died at St. Louis on the West Coast of Africa, having just arrived from Kayes a town in the French Soudan or Hinterland behind the French Guinea. Such is the history of the parasite as far as I can find it. Numerous references are made in many text-books but the above are, I fancy, the only original observations.

With regard to my own case, that of the Mendi abovementioned, the clinical history was as follows. On admission into the hospital the patient was much emaciated and very weak. He had a markedly enlarged and protuberant abdomen. The temperature was slightly above normal and

Krankheiten des Orients, 1847, p. 245.

2 Zeitschrift tir Wissenschaftliche Zoologie, Band iv., s. 65. Science and Practice of Medicine, 1868, vol. i.. p. 650 .

4 Comptes Rendus de la Société de Biologie, 1896, vol. x., series iii., pp. $469-471$. he suffered from a hacking cough with expectoration of a little mucus. He apparently suffered from pain in the abdomen and the lower part of the chest, but it was extremely difficult to be certain of his sensations as no one understood his language. The physical signs which were present in the respiratory organs were those of congestion of the lungs with impaired resonance on both sides and mucoid expectoration in which no parasites were to be seen. There was pain on pressure over the ahdomen. The bowels acted regularly but unfortunately the fæces were not examined. The liver was enlarged but not tender. The spleen was very much increased in size. The heart was normal but the patient was anæmic. When the blood was examined no parasites were to be seen or anything worthy of note. The urinary system was normal, as was the cutaneous system. The patient remained in much the same condition for a few days, but suddenly the temperature rose to $104^{\circ} \mathrm{F}$. and he became rapidly worse and died. He was mainly treated for congestion of the lungs and it was this disease which was the cause of his death.

The post-mortem examination was made about 17 hours after death. The body was much emaciated and the abdomen was protuberant. On opening the abdomen large numbers of parasites (pentastoma constrictum) were observed moving freely in the abdominal cavity over the surfaces of the various organs, to which some were also observed to be attached. The liver contained in its substance and projecting on to its surface a large number of cysts each containing a clear fluid in which lay a single parasite coiled up. Some of these were liberated and found to be alive, and were exactly the same as the pentastomata found free in the peritoneal cavily. No parasites were found in the gall-bladder or in the bile duct. The substance of the liver was congested and the organ was enlarged. The stomach and intestines were not congested, though they were matted together by old peritonitic adhesions. Attached to the surface of the intestines at a few spots parasites were seen firmly fixed by their hooks. On opening the stomach no parasites were seen, but in the small intestine, except the duodenum, there were large numbers of pentastomata. None were seen in the large intestine. At places in the small intestine there were signs as though the parasites were in the act of passing from the lumen of the bowel through the wall of the intestine into the peritoneal cavity. The spleen was markedly enlarged and congested but entirely free from parasites. The kidneys and pancreas were normal. Several parasites were found attached to the peritoneal surface of the bladder, but none were found in the interior or in the wall. The peritoneum everywhere showed signs of old peritonitis, but this was most marked in the region of the liver and the spleen. The diaphragm, except for peritoneal adhesions, was normal, and no parasites. were noticed attached to it. In the chest the heart was normal, but the pericardium was much thickened. The pleura was much thickened on both sides and the lungs were bound down by many old fibrous adhesions. The lungs were markedly congested and cedematous and the bronchi were inflamed. Both projecting on the surface and imbedded in the substance of both lungs there were numerous cysts like those found in the liver and in each of these a parasite was found. No parasites were found in the muscles or among the adipose tissue of the body. The brain and the spinal cord were not examined.

I do not intend to describe the anatomy of pentastoma constrictum in this paper but hope to do so shortly. Nothing is known at present as to the life-history of this parasite or as to the means by which it enters the human body. It appears to me that it enters by some means into the alimentary canal and that from this it proceeds to the liver, the cysts in which appear to be dilated biliary ducts, and into the peritoneum. It also seems as though the lungs were affected through the trachea, as the cysts therein appear like dilated bronchioles. The presence of the parasite in the human body sets up inflammation of the lungs and peritoneum, but it does not appear to irritate the alimentary canal or the liver. The disease appears to last some time before causing the death of the patient, for as far as I could make out the above-mentioned Mendi had been ill a long time. The only possible means of diagnosis would be the presence of the parasite in the fæces in cases of wasting and emaciation in negroes.

There is no described treatment of this disease. It appears to be confined to negroes and the described cases came from 
the island of St. Helena, the city of Kayes on the River Senegal in the French Soudan of West Africa, and this Mendi came from the English colony of Sierra Leone. Pruner does not state where the two negroes who died in Kgypt came from.

In conclusion, I wish to thank Mr. Henderson, the chief medical officer of the Gold Coast Colony, for his kindness in allowing me to record this case.

Cape Cuast.

\section{A CASE OF BILHARZIA OF THE VAGINA.}

\section{Br FRANK COLE MADDEN, M.B, B.S. MELB.} F.R C.S. ENG.,

PROHLSSOR OF SURGERT, EGYPTLAN GOVERXMENT MIDICAL SCHOOL SENIOR SURGEON, KASR-EL-AINI HOSPITAI, CAIRO.

IN spite of the extraordinary prevalence of bilharzia along the course of the urinary tract, and to a less extent in the rectum, among the lower classes of the native population in Egypt, it is rare to find a case in which the primary infection is in the vagiua. Further, notwithstanding its very susceptible surroundings very few instances of secondary raginal infection by extension have been noted. Various explanations have been offered to account for the comparative infrequency of severe bilharzia in the female sex, the most reasonable, perhaps, ascribing it to the different habits of life in the two sexes " and in no way do they differ more than in the frequency and manner in which they bathe. River bathing is but seldom indulged in by women, but in countries in which bilharzia is prevalent the men spend a no inconsiderable portion of their day in the water" (Guillemard). This statement, however, does not apply in its entirety to Egypt where bathing is not at all popular. At the same time the "fellah"-agricultural labourer and the like-does a great deal of paddling in water and moist earth during the day's work. If the theory of infection through the skin is to be accepted this possible water-borne inoculation must be considered. It is certain, on the other hand, that many cases of cystitis in the female and (to a less degree) of vesico-raginal fistulæ are due to bilharzia, which does not appear to take on the same papillomatous growth so characteristic of the disease in the genito-urinary tract of the male sex.

The present case was that of a young Egyptian woman who was sent to me by Dr. Aly Heidar with a view to operation for a tumour of the vagina. She was quite well until about a year ago when she noticed a small pendulous tag in the vagina. She had a little pain over the pubes for a few days at this time. The tag gradually increased in size, fresh pieces appeared and rapidly grew until the vagina was almost completely blocked. There had never been any trouble with the urine but a large piece in the front of the vagina sometimes caused pain during micturition. There were never any rectal, uterine, or bladder symptoms. She had been married for four years and bad never been pregnant. Menstruation had always been regular and was not painful. On examination the mucous membrane of the vagina was much prolapsed all round owing to an extreme laxity of the vaginal walls. A considerable mass of much hypertrophied mucous memk rans could be extruded and the cervix uteri, quite smooth and healthy, could be felt deep down in the midst of this redundant mass of irregularly papillomatous tissue. The uterus was small and freely moveable. The opening of the urethra was bidden by a soft warty mass, but the urethra itself was quite normal. Further examination under an anæsthetic showed that the entire mucous membrane was greatly thickened and hypertrophied owing to a general papillomatous change and almost filled a more than usually capacious vagina. There was a large pedunculated tuft on the anterior wall just behind the orifice of the urethra, and in the rest of the extent of the mucous membrane there were innumerable flat-topped elevations of various sizes intersected in all directions by depressions the depths of which represented the surface of the true mucous membrane. Here and there a more definitely papillomatous formation was present. Looking on the case as a general papillomatous change (? cause) in the vaginal mucous membrane the greater part of the obstructing anterior mass was removed, a catheter being placed in the bladder to prevent injury to the uretbra or bladder during the operation. The edges of the wound were then accurately sutured with fine silkworm gut, and when the operation was complete the outlet of the vagina was very much clearer than before.

The specimen which was examined microscopically by Dr. Symmers presented all the appearances of a bilharzia papilloma and numerous ova were found in the submucous tissue throughout the sections. After this unexpected diagnosis the bladder was carefully examined with the sound - the cystoscope has not yet reached Egypt-but beyond a slight roughness posteriorly nothing abnormal was made out. The urine was microscopically examined on several occasions but no bilharzia ova were discovered. The urethra was quite healthy and the rectum was normal. The condition was, therefore, not due to extension from neighbouring viscera and it was thought possible that it was a case of infection from the husband. His statements, however, did not support this idea. He was a soldier, apparently in perfect health, and had never had any symptoms of bilharzia of the urinary tract or of the rectum. He passed a small stone by the uretbra when he was nine years of age. All stones in Egypt are suspicious of bilbarzia, but other symptoms would certainly have appeared had it been due to this cause in this instance. Further, he stated that at the time of his marriage he noticed that his wife had a small tag in the posterior part of the vagina and this had gradually increased in size. A year or more ago he first noticed the tuft on the anterior wall. Thus, though there are slight discrepancies in the two histories the possibility of infection from the husband can hardly be allowed.

It would appear that this is a case of primary infection of the vagina, the pathology of which is practically identical with that so frequently described in the bladder. Thus Leuckart writes: "One may find on the mucous membrane of the bladder single or sometimes grouped excrescences not unlike condylomata, with or without pedicles, which may present manifold variations of shape and may be as large as a bean. ...... On section the mucous membrane is thickened and the submucous connective tissue hypertrophied. Both are pervaded by a rich network of capillaries, the vessels being sometimes much dilated and here and there changed to ratber large cavities which often contain fullgrown specimens of the distoma. In the parenchyma of the excrescences, which is formed chiefly of the submucous tissue, numerous eggs are found," \&rc. A few weeks before the case described above was admitted to the hospital my colleague, Mr. Frank Milton, removed a piece of a somewhat colloid papillomatous mass from the anterior wall of the vagina close to the cervix uteri, which presented in less degree many of the appearances above detailed. Unfortunately, no microscopical examination was made. The available literature on the subject here is of rather ancient date, but the case is worthy of record as an unusual form of bilharzic infection, the strict localisation of which to the vagina is rather difficult to understand with so many more usual centres of primary infection in such close proximity. Cairo.

\section{Clinitall âdotes:}

\section{MEDICAL, SURGICAL, OBSTETRICAL, AND THERAPEUTICAL.}

\section{A CASE OF PROCIDENT UTERUS TREATED BY QUININE INJECTION.}

By J. Aikman, M.D. Grasg.

A SHORT, thick-set woman, aged 61 years, crippled by chronic deforming rheumatism of the knees and feet, had for many years suffered from prolapse of the uterus. She had borne two children and the perineum was deeply rent at the birth of the second child-now an adult. Her husband was a sea-faring man and for many years had been in an asylum. The bringing up of the children had been accomplished by laborious work as a charwoman on the part of the mother. Seven years since complete procidentia took 